\title{
A case of Shapiro's Syndrome in an African young man
}

\author{
Mwita J ulius Chacha ${ }^{1}$, Omech Bernard ${ }^{2}$, Siamisang Keatlaretse ${ }^{3}$, Bose Humphrey ${ }^{4}$ \\ 1. Department of internal medicine, University of Botswana, Gaborone, Botswana. 2. Department of medicine, University \\ of Botswana, Gaborone, Botswana. 3. Department of Internal Medicine, University of Botswana, Gaborone, Botswana. \\ 4. University of Botswana, Gaborone, Botswana.
}

Correspondence: Omech Bernard. Address: Department of medicine, University of Botswana, Gaborone, Botswana. Email: bgomech@gmail.com

Received: March 5, 2015

DOI : $10.5430 /$ crim.v2n2p72
Accepted: March 24, $2015 \quad$ Online Published: April 2, 2015

URL: http://dx.doi.org/10.5430/crim.v2n2p72

\section{Abstract}

Shapiro's syndrome is a rare congenital neurological disease characterized by episodes of excessive sweating and hypothermia, and by complete/partial agenesis of the corpus callosum. We report an 18 year-old male who was referred to Princess Marina Hopsital with a longstanding history of episodic shaking chills, excessive sweating, fatigue, and unsteady gait. During the episodes, he was bradycardic (pulse rate of less than 36 beats/minute), with blood pressure of less than $80 / 45 \mathrm{mmHg}$, and his axillary body temperatures were unrecordably low. Neurologic examination showed cerebellar signs. The MRI of the brain revealed agenesis of the corpus callosum with no other abnormalities. The patient responded to clonidine therapy. Shapiro's syndrome is an important consideration when evaluating a patient with episodic hyperhidrosis and hypothermia. The syndrome is rare worldwide and to the best of our knowledge, this report constitutes the first documentation of a case from Africa.

\section{Keywords}

Shapiro's syndrome, Corpus callosum agenesis, Africa

\section{Introduction}

Shapiro's syndrome is a rare congenital neurological disease thought to be caused by a hypothalamic lesion, first described by Shapiro and Plum in $1969^{[1]}$. It is characterized by episodes of excessive sweating and hypothermia, and by agenesis of the corpus callosum ${ }^{[1]}$. Symptoms can begin at any age, and they may include episodic confusion, decreased level of arousal, hypothermia, bradycardia and diaphoresis and eventual resolution within hours ${ }^{[1,2]}$. Diagnosis is based on a typical history and confirmation of partial or complete agenesis of the corpus callosum on magnetic resonance imaging $(\mathrm{MRI})^{[2,3]}$. Most case reports in the literature described patients from high income countries. We hereby describe a case of a young man from Botswana with Shapiro's syndrome.

\section{Case report}

An 18-year-old man was referred to Princess Marina Hospital in Gaborone with a history of episodic shaking chills, excessive sweating, fatigue, and gait unsteadiness. The episodes had increased over the past three years, and at the time of admission he had about four episodes daily. These episodes occurred during morning hours and were associated with 
perception of extreme cold, bed-shaking chills and drenching sweats. One episode would last for about two hours, leaving him extremely exhausted. His parents described a slowly but progressive slurring of speech and unsteadiness on walking. He had multiple visits to different health facilities, where laboratory tests did not reveal the cause. The patient had no history of any seizure disorder, head injury or other chronic illnesses. His delivery was reportedly normal but he had delayed developmental milestones and later failure to progress beyond standard three at school.

At admission, physical examination showed a normal body habitus and euvolaemia. He was bradycardic (pulse rate 36 beats/minute), with blood pressure of $75 / 45 \mathrm{mmHg}$, and his axillary body temperature (using digital thermometer) was unrecordably low. The outdoor temperature was about 35 degree Celsius. Neurologic examination revealed cerebellar ataxia and dysarthria. .

During his stay in the medical ward, we observed multiple symptomatic episodes in which the patient was hypotensive ( $<$ 80/45 mmHg), bradycardic, hypothermic and sweating profusely. No associated postural drop in blood pressure was detected. His axillary body temperature were often unrecordable and when recorded, the readings remained below $35^{\circ} \mathrm{C}$ (normal range $36.12^{\circ} \mathrm{C}-37.4^{\circ} \mathrm{C}$ ) celsius. It was summer and the outdoor temperature ranged between 30 and 35 degree Celsius.

His initial laboratory results showed a white blood cell count (WBC) of $1.89 \times 10^{3} / \mu \mathrm{L}\left(4-10 \times 10^{3} / \mu \mathrm{L}\right.$, haemoglobin (Hb) of $10.1 \mathrm{~g} / \mathrm{dl}(12 .-15 \mathrm{~g} / \mathrm{dL})$, Haematocrit (Hct) of 31.6\%(40-50\%), platelet count of $108 \times 10^{3} / \mu \mathrm{L}\left(150-450 \times 10^{3} / \mu \mathrm{L}\right)$, and a normal peripheral blood smear. Renal function, blood glucose, serum electrolytes, thyroid function and cortisol level were normal. There was a mild elevation of liver enzymes ALT (Alanine Amino Transferase)-76 IU/L(10-34 U/L); AST (Aspartate Amino Transferase)-52(10-34 U/L); GGT (Gamma-Glutamyl Transferase)-15(11-50U/L); ALP (Alkaline Phosphatase)-101(45-115U/L). Lipid profile, serum ceruloplasmin, catecholamine and metanephrines were all normal. HIV serology was negative. A 24-hour urine study showed normal vanillylmandelic acid level.Abdominal ultrasound findings and chest radiography were also normal. During episodes, the patient was treated with warm blankets and supportive fluid replacement.

A central cause of the hypothermia was suspected and MRI of the brain was done which revealed the complete absence of the corpus callosum with no other abnormalities (see Figure 1A and B). A diagnosis of Shapiro's syndrome was therefore made based on a triad of hyperhidrosis, hypothermia, and agenesis of the corpus callosum.
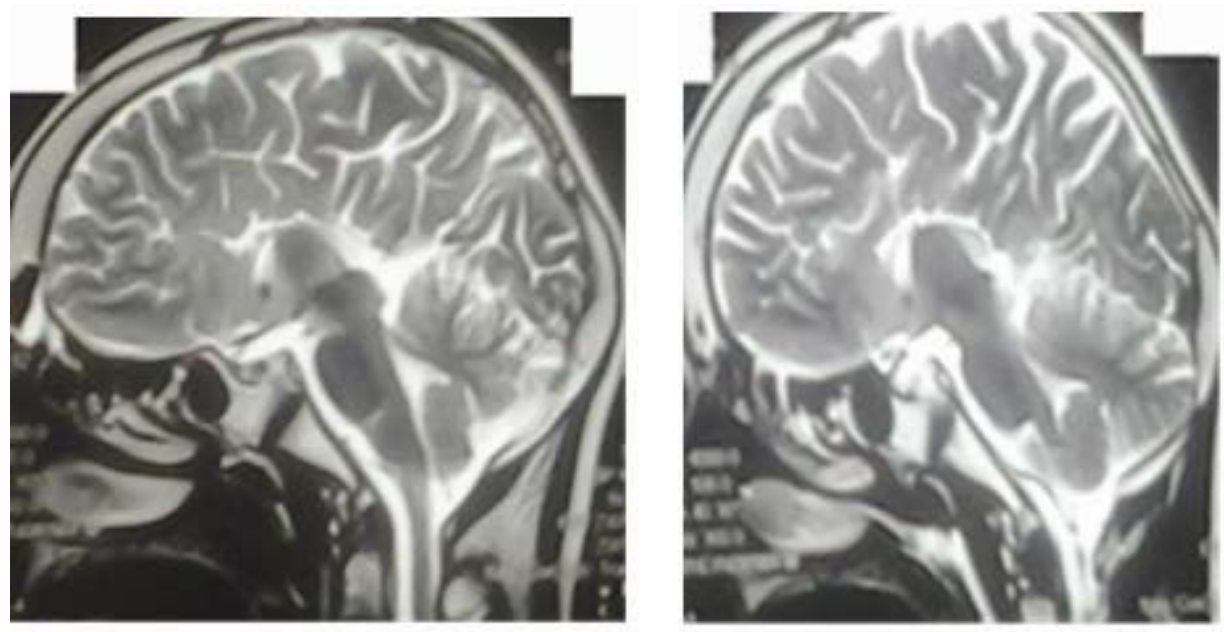

Figure 1A. Sagittal T1-weighted images showing corpus callosum agenesis suggestive of Shapiro syndrome 

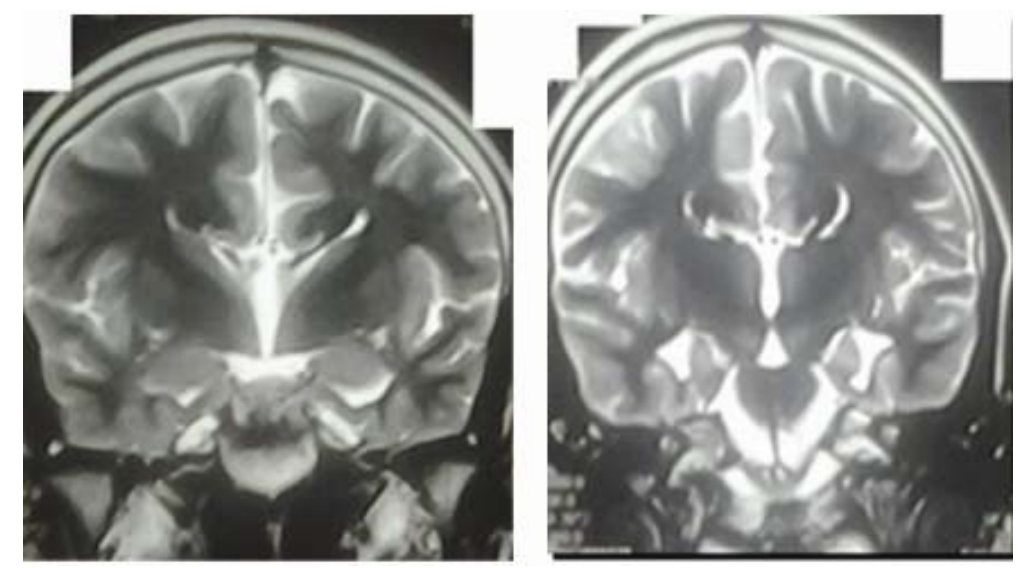

Figure 1B. Viking helmet appearance assumed by the lateral ventricles in the absence of the corpus callosum

By the third week from admission, the patient had a further drop in white blood cells (WBC) count $\left(1.5 \times 10^{3} / \mu \mathrm{L}\right)$ and haemoglobin $(9.7 \mathrm{~g} / \mathrm{dL})$ levels. However, his platelet count increased to $197 \times 10^{3} / \mu \mathrm{L}$. The patient was initiated on clonidine 100mcg every eight hours. His hypothermic episodes slowly decreased over the following two weeks, and his WBC count $\left(2.0 \times 10^{3} / \mu \mathrm{L}\right)$ and haemoglobin $(10.2 \mathrm{~g} / \mathrm{L})$ slightly improved. However, his platelet count remained low $\left(104 \times 10^{3} / \mu \mathrm{L}\right)$. At discharge, the episodes had decreased to less than three times in a week.

\section{Discussion}

Since its first description in 1969, fewer than 50 cases of Shapiro syndrome have been described, and to our best knowledge none of these cases have been described from Africa ${ }^{[1,2,4]}$. The pathophysiology of Shapiro's syndrome is related to a defect of central temperature control mechanisms. It is postulated that widespread degenerative processes, neurochemical dysfunction, and inflammatory processes associated with partial or complete agenesis of corpus callosum affect thermoregulatory centres in the hypothalamus ${ }^{[3,5]}$. Episodic hypothermia is assumed to be due to a paroxysmal resetting of the hypothalamic thermostat to a lower temperature set point ${ }^{[3,6]}$. As a result, patients with Shapiro's syndrome tend to sweat first to lower their temperatures to these lower set points, and would tend to sustain a temporarily lowered temperature "set point" during episodes of hypothermia ${ }^{[7]}$.

With hypothermia, patients manifest numerous multi-system complications that may include bradycardia, paradoxical sweating, thrombocytopenia, anaemia, psychiatric disturbance, hepatitis, gastrointestinal haemorrhage and raised inflammatory markers ${ }^{[8]}$. In our patient, bradycardia, haematological abnormalities, mild transaminitis and neurological manifestations were observed. His haematological manifestations ranged from mild thrombocytopenia to pancytopenia. These abnormalities may be explained by either transient bone marrow suppression or splenic/ hepatic sequestration of blood cells secondary to hypothermia ${ }^{[9]}$. Hypothermia may also increase vessel permeability and diuresis with consequent haemoconcentration of red blood cells ${ }^{[8]}$. However, this was not observed in our patient who had normal haematocrit values throughtout the admission period. It is also postulated that during hypothermia, the patient's cardiac pacemaker cells decrease their spontaneous depolarisation resulting in bradycardia and hypotension ${ }^{[10]}$.

Callosal anomalies may be associated with a variety of other brain malformations, with different manifestations ${ }^{\text {[11] }}$. In our patient, cerebellar signs and mental retardation were evident by dysathria, unstable gait and poor cognitive ability in class.

A diagnosis of Shapiro syndrome requires a combination of a thorough clinical history, physical examinations and imaging ${ }^{[1,2]}$. As in our patient, MRI of the brain shows a classical agenesis of corpus callosum ${ }^{[2]}$. Other suggested 
investigations include electroencephalogram (EEG) to evaluate seizure activity, and screening for infection and metabolic disorders ${ }^{[2]}$.

Clonidine, alpha-2 adrenceptor agonist has been used successfully in symptomatic treatment in patients with Shapiro's syndrome ${ }^{[12]}$. It is thought to work by acting on hypothalamic thermoregulation ${ }^{[12]}$. Treatment with other centrally acting medications that mimic the neurotransmitters affecting the hypothalamus (dopamine, acetylcholine, serotonin, prostaglandins and catecholamines) has also been used with remission of symptoms ${ }^{[5,7,10]}$.

\section{Conclusion}

Shapiro's syndrome is a rare condition that must be considered when evaluating a patient with episodic hyperhidrosis and hypothermia.

\section{Conflict of interest}

No conflict of interest to be declared.

\section{Acknowledgements}

We wish to thank the patient for accepting that this case be published and Drs. Francesca Cainelli and Daniel Baxter for their review of the manuscript.

\section{References}

[1] Shapiro WR, Williams GH, Plum F. Spontaneous recurrent hypothermia accompanying agenesis of the corpus callosum. Brain. 1969; 92(2): 423-36. PMid:5790256 http://dx.doi.org/10.1093/brain/92.2.423

[2] Blondin NA. Diagnosis and management of periodic hypothermia. Neurology: Clinical Practice. 2014; 4(1): 26-33. http://dx.doi.org/10.1212/01.CPJ.0000437350.47610.3a

[3] Shenoy C. Shapiro syndrome. QJM. 2008; 101(1): 61-2. PMid:18203725 http://dx.doi.org/10.1093/qjmed/hcm106

[4] Pazderska A, O'Connell M, Pender N, et al. Insights into thermoregulation: A clinico-radiological description of Shapiro syndrome. Journal of the Neurological Sciences. 2013; 329(1): 66-8. PMid:23578790 http://dx.doi.org/10.1016/j.jns.2013.03.014

[5] Kloos RT. Spontaneous periodic hypothermia. Medicine. 1995; 74(5): 268-80. PMid:7565067 http://dx.doi.org/10.1097/00005792-199509000-00004

[6] Albon L, Kenton A, MacGregor E, et al. HYPOTHALAMIC DYSFUNCTION IN SHAPIRO'S SYNDROME MAY CAUSE ABNORMALITIES OF THIRST AND APPETITE PERCEPTION. 2002.

[7] Klingler ET, Meyer K. Shapiro's syndrome: a renewed appreciation for vital signs. Clinical Infectious Diseases. 2004; 38(10): e107-e8. PMid:15156503 http://dx.doi.org/10.1086/386337

[8] Alty J, Ford H. Multi-system complications of hypothermia: a case of recurrent episodic hypothermia with a review of the pathophysiology of hypothermia. Postgraduate Medical Journal. 2008; 84(992): 282-6. PMid:18644917 http://dx.doi.org/10.1136/pgmj.2007.066050

[9] Roeker LE, Gupta V, Gonsalves WI, Wolanskyj AP, Gangat N. Cyclic Bicytopenia in a Patient with Shapiro Syndrome. Case Reports in Hematology. 2013.

[10] MORRIS DL, CHAMBERS HF, MORRIS MG, SANDE MA. Hemodynamic characteristics of patients with hypothermia due to occult infection and other causes. Annals of internal medicine. 1985;102(2):153-7. PMid:3966751 http://dx.doi.org/10.7326/0003-4819-102-2-153

[11] Hetts SW, Sherr EH, Chao S, et al. Anomalies of the corpus callosum: an MR analysis of the phenotypic spectrum of associated malformations. American Journal of Roentgenology. 2006; 187(5): 1343-8. PMid:17056927 http://dx.doi.org/10.2214/AJR.05.0146

[12] Walker B, Anderson J, Edwards C. Clonidine therapy for Shapiro's syndrome. QJM. 1992; 82(3): 235-45. PMid:1631258 